\title{
Interpretação de textos, de história e de intérprete
}

José Adilçon Campigoto

Universidade Estadual do Oeste do Paraná

\section{RESUMO}

Estudo sobre a hermenêutica filosófica e a importância de seu uso para a escrita da história. As fontes utilizadas são um texto escrito por Ronaldo Vainfas, outro por Ciro Flamarion Cardoso e um terceiro, produzido por estes dois escritores em conjunto. Tais textos pertencem ao livro intitulado Domínios da história: ensaios de teoria e metodologia, organizado pelos autores supra citados. A partir das fontes, tento evidenciar as tradições nas quais me movimento e os métodos utilizados pelos por Ciro e Vainfas

Palavras-chave: Hermenêutica. Texto. Contexto. História.

\section{ABSTRACT}

Study on the philosophical hermeneutics and the importance of its use for the writing of history. The used sources are a text written for Ronaldo Vainfas, another one for Ciro Flamarion Cardoso and one third, produced for these two writers in set. Such texts belong to the intitled book Dominios da história: ensaio de teoria e metodogia, organized for the authors supply cited. From the sources, I try to evidence the traditions in which I myself movement and the methods used for the ones for Ciro and Vainfas.

Keywords: Hermeneutic. Text. Context. History.

Antes de iniciarmos esta reflexão sobre a importância da hermenêutica na escrita da história convém um esclarecimento a respeito da noção de texto. A explicação se faz necessária porque nós, historiadores, geralmente operamos com a noção de texto mesmo quando recorremos à oralidade, ou fazemos estudos de imagens, de situações e de acontecimentos. Temos adotado, via de regra, o princípio de que os textos devem ser compreendidos em seus contextos, premissa derivada do método interpretativo conhecido como hermenêutica romântica ou contextual, proposto por Dilthey.

No dizer de Hans-Georg Gadamer, um método sistemático para a compreensão da história:

(...) não se encontra obviamente em Ranke, nem no arguto metodólogo Droysen, mas somente em Dilthey, que toma conscientemente a hermenêutica ro- 
mântica e a amplia até fazer dela uma historiografia e até uma teoria do conhecimento das ciências do espírito. A análise lógica de Dilthey do conceito do nexo na história representa, segundo a questão em causa, a aplicação do princípio hermenêutico, segundo o qual as partes individuais de um texto só podem ser entendidas a partir do todo, e este somente a partir daquelas, sobre o mundo da história. Não somente as fontes chegam até nós como textos, mas também a realidade histórica é em si um texto que deve ser compreendido. Com esta transferência da hermenêutica para a historiografia, Dilthey tornava-se o intérprete da escola histórica. ${ }^{1}$

A proposta de Dilthey é extremamente conhecida por todos nós, e do ponto de vista teórico é largamente aplicada e consiste em analisar os textos a partir do lugar de sua produção, isto é, do seu contexto. Dilthey também ampliou o conceito de texto, que passou a ser estendido a qualquer objeto de compreensão, ou seja, sua proposta hermenêutica comporta o princípio de que a partir de um determinado contexto qualquer objeto pode ser lido como um texto. Assim, podemos compreender por que, tantas vezes nós, historiadores, recorremos à noção de texto; evidentemente, utilizamos o método romântico.

O método proposto por Dilthey provoca uma espécie de enredamento nas aporias do historicismo, como demonstrou Gadamer, porque o quadro contextual que oferece sentido aos textos/objetos não é dado pelos deuses ou pela natureza, e sim elaborado pelos intérpretes. Logo, quando utilizamos o procedimento contextual, somos obrigados a inventar os contextos, do contrário, os sentidos de nossos textos não se completam. Contexto é, portanto, uma peça do método romântico estendida sobre o mundo histórico, mundo concebido como o grande escrito da vida. Além de fundamentar-se num conceito demasiado amplo de texto e de funcionar como o ponto determinante na construção dos contextos, o procedimento romântico engloba uma terceira falha, a mais grave de todas.

Quando interpretamos os textos/objetos tentando encontrar o seu sentido nos contextos, o produto de nosso trabalho como intérpretes jamais é considerado como objeto de análise, porque temos a ilusão de poder construir novos sentidos rompendo com o mundo da pré-compreensão, isto é, dos sentidos transmitidos de uma geração para outra.

Foi assim que os textos e seus contextos tornaram-se como que macroconceitos da escrita da história. A constatação deste acontecer no âmbito da linguagem e o contato com alguns comentários sobre a hermenêutica, que apontaremos adiante, levaram-nos a tecer algumas ponderações referentes aos conceitos e às operações textuais no fazer interpretativo. Escolhemos três 
artigos pertencentes ao livro Domínios da história: ensaios de teoria e metodologia, organizado por Ciro Flamarion Cardoso e Ronaldo Vainfas, para estabelecer a discussão. Dois destes escritos são referentes à arte da interpretação e os utilizamos como contrapontos a fim de elucidar a proposta de Gadamer. Ao mesmo tempo, recorremos a um terceiro escrito, e empregamos todos como fontes para identificar o método compreensivo aplicado pelos seus escritores.

\section{INTERPRETAÇÃO PSICOLÓGICA}

Há, entre os documentos escolhidos, um especificamente destinado à reflexão metodológica sobre a interpretação de textos e à apresentação de propostas de trabalho aos historiadores interessados no fazer interpretativo. Trata-se do capítulo 17 do livro acima citado e tem o título: História e análise de texto. O texto é iniciado por um subtítulo insinuante: Os historiadores e o trabalho com os textos: da hermenêutica do método tradicional aos contatos com a lingüística e com a semiótica.

Dizemos insinuante porque as expressões "hermenêutica do método tradicional" e "domínios da história" provocam expectativas de sentido sobre a coisa que se irá ler, e se o texto se mantiver fiel ao tema, versará sobre o método hermenêutico utilizado pelos historiadores da chamada história tradicional.

Convém, no entanto, esclarecer que o qualificativo tradicional torna-se aqui uma das balizas da reflexão, tanto para nós quanto para Cardoso, Vainfas e nossos leitores. Se pertencemos à tradição iluminista, a palavra tradicional deve equivaler a coisa ultrapassada, antiga e equivocada, ou coisas utilizadas ainda somente por pessoas ignorantes. A necessidade de pontuar tal conceito já é um indicativo de que a perspectiva iluminista não cessou no século XIX e não apresenta incompatibilidades maiores com outras filosofias, tais como o positivismo, o materialismo, e até mesmo com a fenomenologia ou com qualquer outra forma de pensamento, bastando para isso que esteja vinculada à idéia de progresso. Portanto, sempre que aceitamos a equivalência entre os termos tradicional e atrasado, tradicional e ultrapassado, situamo-nos na tradição iluminista e na doutrina do progresso.

Na tese oposta, consideramos o tradicional como algo válido e verdadeiro, pois significa que a coisa resistiu ao tempo. Tal posição indica a pertença à tradição historicista. Logo, quando compreendemos o tradicional como algo duradouro, consolidado, verdadeiro e eficiente, nos movemos no horizonte do historicismo.

Afastando-nos um pouco do discurso das Luzes e do historicismo, a pa- 
lavra tradição significará para nós, doravante, o conhecimento transmitido que forma o nosso horizonte de compreensão. Os sentidos comunicados de uma geração para outra formam o mundo da pré-compreensão necessário para a efetuação de toda interpretação, por mais isenta que desejemos ou suponhamos que elas sejam. Este cuidado nos é imprescindível para que não projetemos nosso modo de compreender sobre o texto de Vainfas e Cardoso, o que nos levaria, talvez, a levantar falsas acusações, tais como supor que segundo estes autores a hermenêutica seja algo ultrapassado. Deste modo, os classificaríamos como iluministas e, do contrário, os enquadraríamos no historicismo; mas o objetivo aqui não é rotular historiadores.

Então, vamos nos ater ao escrito, com expectativas de sentidos, evidentemente. No primeiro parágrafo do capítulo 17 encontra-se o seguinte enunciado:

(...) há historiadores que crêem ser a atitude hermenêutica - de que tanto se fala hoje em dia — algo recente. Ledo engano. Já o venerável manual de Langlois e Seignobos, que data dos últimos anos do século XIX, criticava os que liam textos com a preocupação de neles encontrarem informações diretas.. ${ }^{2}$

Estabelecendo um confronto entre o texto citado e o título, notamos prontamente uma certa ampliação do tema, pois já não estamos discutindo o método tradicional ou algum procedimento particular. A discussão foi ampliada para a "atitude hermenêutica de que tanto se fala hoje em dia", um fenômeno bem mais amplo do que a proposição de Langlois e Seignobos.

Ocorre que, entre outras coisas, a palavra método foi utilizada como sinônimo do vocábulo atitude e existem algumas diferenças entre este dois termos que merecem alguma explicitação. Entendemos que método significa procedimento, processo, arte, técnica, artifício e tecnologia, ao passo que atitude equivale a jeito, maneira, modo, caráter, estilo e costume. Em todo caso, na língua portuguesa método não equivale a atitude, e isto é um ponto decisivo para a discussão da hermenêutica na perspectiva gadameriana, que temos adotado.

Consideramos extremamente relevante a discussão sobre a antigüidade dos métodos de interpretação, mas pensamos não haver grandes problemas com as formas de pensamento ou técnicas de trabalho pelo simples fato de serem antigos. A atitude hermenêutica, no entanto, é algo mais amplo do que o método encontrado no manual de Langlois e Seignobos e apontado por Vainfas e Cardoso. A chamada atitude hermenêutica, bem longe de ser um método, consiste numa concepção filosófica a respeito da compreensão e da linguagem. O procedimento descrito pelos autores como: 
(...) crítica interna dos testemunhos, cuja fase inicial é exatamente a hermenêutica ou crítica de interpretação — também chamada de crítica positiva: "a análise do conteúdo do documento e a crítica positiva de interpretação" seriam necessárias para firmar certeza do que o autor quis $\operatorname{dizer}^{3}(\ldots)$

(...) não vai além de um modelo interpretativo aplicado ao campo da história. A reflexão histórica porém não esgota o fenômeno da interpretação e a atitude hermenêutica não caberia em manuais sem o ônus de perdas lamentáveis.

Não seria justo pressupor que a vinculação da atitude hermenêutica a Langlois e Seignobos, conforme aparece no texto de Vainfas e Cardoso, foi urdida propositalmente objetivando desqualificar a arte da interpretação. Se assim o fizéssemos, estaríamos utilizando a mesma metodologia extraída do manual que, em princípio, não necessita ser venerado, pois, ao que podemos compreender, nele está prescrita a sugestão de “... recriar mentalmente as operações que se deveriam ter processado no espírito do autor" " para ter a certeza do que eles quiseram dizer.

A recomendação de Langlois e Seignobos para quem quiser fazer interpretação de textos consiste em que o intérprete deve imaginar as coisas que passaram pela mente do autor no momento em que escrevia. Os escritores do manual sugeriam apenas a utilização de um dos procedimentos hermenêuticos. Método antigo, mas atual e usado abundantemente na escrita da história porque se trata de um artifício que empregamos para conferir sentido aos nossos discursos. Cardoso e Vainfas utilizam-se, e muito, deste recurso, como esperamos demonstrar.

Antes, porém, deve ficar claro que, se não estivermos atentos, poderemos estar utilizando este método devido ao seu uso generalizado. O processo ocorre no âmbito da interpretação, principalmente de textos, e partimos do princípio de que um escrito somente se torna compreensível quando o intérprete consegue captar o que o autor quis dizer, e não o que efetivamente disse. $\mathrm{O}$ método psicológico é associado ao romântico, e em virtude da ampliação do conceito de texto, consideramos os escritos e os acontecimentos como algo que somente adquire sentido se forem descobertas as intenções ou interesses dos escritores ou dos protagonistas sobre o fato que está sendo interpretado.

$\mathrm{O}$ recurso que passava pela mente de um autor para que o intérprete pudesse captar o sentido de seu texto foi sistematizado por Friedrich D. E. Schleiermacher no início do século XIX. Filólogo, teólogo e filósofo, empenhou-se no trabalho de conferir cientificidade à pratica da interpretação e na construção de um método capaz de superar a exegese bíblica e a filologia. A regra básica para a interpretação dos Textos Sagrados, mais aceita pelos intelectuais cristãos durante a Idade Média, era confrontar os textos de difícil 
compreensão com o todo da mensagem cristã, e se por acaso o sentido oculto não aparecesse, dever-se-ia confrontá-los com os ensinamentos dos grandes pensadores do cristianismo. Era uma forma de interpretação fundamentada na doutrina patrística que sofreu grandes modificações diante do racionalismo, forma de pensamento que propiciou a reabilitação da filologia clássica. Tal ressurgimento foi corroborado pela reforma luterana, pois Lutero questionou as bases da patrística e sustentou que o sentido oculto dos enunciados bíblicos deveria ser encontrado no Texto Sagrado mesmo, isto é, descartou a necessidade da recorrência aos "antigos sábios católicos".

Schleiermacher, por sua vez, estendeu o método filológico para a compreensão de qualquer texto, mas enfrentou o problema da autoria, pois quando se tratava de interpretar Texto Sagrados, o intérprete necessitava admitir o problema da verdade e dos equívocos contidos nos textos. Ora, os autores dos textos profanos ${ }^{5}$ são considerados falíveis porque, ao contrário do divino, não podem transportar para o texto tudo aquilo que pensam. Logo, para compreender seus escritos e identificar seus erros seria necessário recriar as operações mentais que fizeram no momento da escrita. Esta também foi a recomendação metodológica feita por Langlois e Seignobos.

O método proposto por Schleiermacher é denominado, por Gadamer, de hermenêutica psicológica e fundamenta-se no

(...) postulado de que importa compreender um autor, melhor do que ele próprio teria se compreendido - uma fórmula que, desde então, tem sido repetida incessantemente, e em cujas interpretações cambiantes caracteriza-se toda a história da hermenêutica moderna... ${ }^{6}$

Conforme Gadamer, para Schleiermacher, "o ato da compreensão é realização re-construtiva de uma produção. Tem que nos tornar conscientes de algumas coisas que ao produtor original podem ter ficado inconscientes".

A tentativa de captar as coisas que ficaram inconscientes ao intérprete original pode resultar na obtenção de interpretações lógicas e coerentes, mas a falha do método consiste em partir do pressuposto que somente os autores dos textos e os protagonistas dos acontecimentos que interpretamos são inconscientes. Além disso, a operação reconstrutiva é a sua própria debilidade, porque a tentativa de recriar as ações que se deveriam ter processado no espírito de um autor implica imaginar os seus interesses, as suas pretensões, as suas ambições, os seus objetivos, e assim por diante, atitudes que jamais podem ser comprovadas.

Debilidades à parte, o procedimento psicológico é freqüentemente utilizado em conjunto com o método romântico proposto por Dilthey. Como já 
vimos, este autor ampliou o conceito de texto para qualquer fenômeno, ampliando ainda mais o conceito de autoria porque, sendo o mundo histórico considerado como um grande escrito, todos os sujeitos podem ser classificados como autores. $\mathrm{O}$ afrouxamento dos conceitos de texto e autoria possibilitou a utilização, em larga escala, dos métodos psicológico e romântico em várias áreas do saber. No campo da história, por exemplo, o emprego destes dois métodos é bem visível nos textos que partem do princípio de que as representações do social são construídas de acordo com os interesses dos sujeitos que as criam. O problema é que os interesses são sempre deduzidos.

Já vimos as dificuldades e as aporias a que a utilização da hermenêutica romântica conduz. A falha da hermenêutica psicológica reside mesmo no fato de que jamais poderemos demonstrar os reais interesses de um autor, a menos que estejam literalmente expressos. Por este motivo, tentaremos compreender os texto de Vainfas e Cardoso identificando os procedimentos hermenêuticos por eles utilizados, enquanto evidenciamos nosso modo de interpretar e evitamos recorrer à psique dos autores.

Cardoso escreveu na introdução aos Domínios da história que às vezes a falta de preparo filosófico e científico dos historiadores “... os faz embarcar em canoas que lhes parece ir no sentido por eles pretendido, sem verificar se estão ou não furadas". ${ }^{8} \mathrm{O}$ enunciado é lógico e faz sentido, porque a falta de preparo filosófico e científico serve como explicação para o fato de os historiadores poderem subir nas embarcações sem verificar antes o estado em que se encontram. Entendemos que sempre pode haver alguma espécie de vacilo na produção do conhecimento, uma vez que o universo não se resume à ciência e à filosofia. Tais disciplinas são constituídas por conjuntos de enunciados verificáveis ou aceitáveis dos quais dependem os sentidos dos termos empregados. Por exemplo, os termos "lhes parece" e "pretendido" têm a ver com as intenções dos sujeitos e indicam o uso da interpretação psicológica.

Examinemos, porém, a canoa. O uso da figura da embarcação ou do navegador que viaja para alcançar o conhecimento é uma tradição bem antiga no Ocidente. Guilhermo Giucci fez um excelente estudo acerca das sucessivas metamorfoses da figura do navegante, da exploração dos mares desconhecidos e da "nau do saber". Partiu do relato da morte de Ulisses, descrita por Dante na Divina Comédia. Conforme seu texto, o herói,

(...) depois de separar-se de Circe, nada pode refrear seu ardente desejo de conhecer o mundo, os vícios e as virtudes dos humanos (...) encontra-se no mar Mediterrâneo com um único navio e alguns companheiros fiéis (...). Além deles se estende um mar sem limites, tenebroso, o verde mar da escuridão. ${ }^{9}$ 
Neste tipo de narrativa, que podemos considerar como uma tradição, o mar freqüentemente representa o desconhecido, despertando certas emoções tais como o medo e a curiosidade. Giucci concluiu que, na Divina Comédia, o temor é ressaltado e o desejo de conhecer, reprovado, porquanto o "Ulisses de Dante interna-se no oceano Atlântico para alcançar a virtude e o conhecimento mas naufraga na costa de uma terra ignota". ${ }^{10}$ A narrativa de Dante pode nos causar assombro e insegurança, mas nem toda aventura do conhecimento será trágica por isso. A moral da tradição grega, conforme depreende-se do texto de Giucci, pode ser outra porque

(...) o remoto e o maravilhoso se entrelaçam na épica homérica... Odisseu não recua diante do perigo monstruoso interposto em seu caminho de regresso a Ítaca. Ao contrário, o incentiva, aumentando sua curiosidade em conhecer as terras e os costumes dos ciclopes e ouvir o canto mortal das sereias. ${ }^{11}$

A oposição entre a criação do assombro e o incentivo da curiosidade talvez seja o resultado do contato entre a tradição cristã e a grega, que gerou um paralelo entre a figura de Cristo e a de Ulisses, conforme apontou Giucci. A nave seria um ponto de articulação, uma vez que "para os primeiros padres, a imagem da barca cruzando o mar se converteu em referência emblemática da Igreja militante deste mundo..." e na tradição hagiográfica, "Deus é o leme da nau. 'Ele' sopra as velas e inevitavelmente guia a peregrinação rumo à meta desejada”. ${ }^{12}$ Se a igreja é a barca, Deus é o leme e os cristãos os navegantes, e isto representa a epopéia cristã na qual a busca de um certo tipo de conhecimento é incentivada. A repressão da curiosidade ocorre em relação a um modo de investigação que não segue os parâmetros cristãos. A barca pagã naufraga enquanto a cristã cruza os mares, e nisto identificamos uma tradição segundo a qual não se deve buscar o conhecimento fora dos padrões estabelecidos.

A tragédia de Ulisses como figura da coação doutrinária é obviamente uma das muitas possibilidades de leitura. Giucci, por exemplo, interpretou as narrativas de viagem, especialmente a de São Brandão, como uma espécie de estilo literário próprio de um contexto em que as lendas e as ciências se fundiam. Disse, também, que a metáfora do viajante homérico não representa necessariamente o desejo de conhecer mundos e espaços ignotos, e sim a pilhagem e a exploração realizadas pelos gregos.

A interpretação feita por Giucci, como se vê, fundamenta-se na recorrência a um contexto explicativo e faz sentido, mas mesmo que nos escritos homéricos a nave do conhecimento esteja em outra acepção, tal figura é utilizada: a navegação como metáfora do conhecimento; a barca como seu veículo e instrumento. O texto de Cardoso e Vainfas é a prova documental de sua 
aplicação porque refere-se ao preparo intelectual dos historiadores que, se não for suficiente, os faz embarcar em canoas furadas.

Verificar, antes, se o barco está ou não "fazendo água” pode ser considerado como um bom conselho em termos de segurança e preservação da vida, especialmente para quem não sabe e nem se atreve a nadar. Há, todavia, quem aconselhe atitudes mais arrojadas. Desta maneira Nietzsche escreveu:

(...) conhecer: este é o prazer para quem tem a vontade do leão! Mas, quem ficou cansado, esse se tornará apenas um ser passivo, ao sabor de todas as ondas... Aí está o barco - lá fora, talvez se rume para o grande nada. Mas quem quer embarcar-se nesse "talvez"? Nenhum de vós quer embarcar no barco da morte! Como, então, pretendeis estar cansados do mundo?... Mas é preciso ter mais coragem para pôr fim à própria vida do que para dar começo a um novo verso: sabem-no todos os médicos e poetas. ${ }^{13}$

O apelo nietzscheano pode ainda ser radicalizado, pois há quem sugira que ateemos fogo ao barco das verdades estabelecidas e nos atiremos no grande oceano das aventuras do conhecimento. Pensamos que a prudência é uma boa virtude, mas permanecer no cais esperando a certeza de que nada acontecerá às nossas embarcações pode custar um preço demasiadamente alto, além de ser muito cômodo. Afinal, o preparo filosófico e o científico não garantem totalmente nossos acertos.

A utilização da figura da nave do conhecimento, no texto de Cardoso, torna evidente o pertencimento do autor e do intérprete a uma determinada tradição de fidelidade, ou então, de questionamento ao mundo do saber estabelecido. Consideramos não ser necessário atear fogo ao barco, nem menos dormir no cais, visto que podemos consertar as canoas enquanto navegamos, isto é, o preparo filosófico e científico pode se dar durante a produção do conhecimento.

O autor, porém, não escreveu que estes "alguns" historiadores têm medo do desconhecido, mas inferimos que, segundo ele, trata-se de pessoas imprevidentes movidas por algumas pretensões. Como o texto relata, estes "navegantes" entram sem uma devida checagem nas suas embarcações porque elas lhes parecem ir no sentido por eles pretendido. Logo, as causas da sua imprudência são a falta de preparo e a pretensão de ir a algum lugar para onde as canoas parecem dirigir-se. Estão em jogo o preparo, a aparência e a vontade.

Os julgamentos por aparência podem ser ligados facilmente à falta de preparo, já que tanto a filosofia quanto a ciência, na tradição ocidental, representam instrumentos úteis para que o ser humano treine seu olhar e veja o mundo para além dos aspectos exteriores. Trata-se do mito do olho clínico. 
A dificuldade reside em demonstrar que os outros enxergam e se guiam pelas aparências, sendo que alguns fenomenólogos partem do princípio de que conhecemos basicamente os aspectos exteriores dos fenômenos. Além disso, é possível que façamos projeções quando afirmamos que os outros vêem somente a exterioridade das coisas, e então abre-se o espaço das teorias psicológicas.

No texto de Cardoso, alguém pretende ir a algum lugar e parece-lhe que a coisa vai naquela direção. A interpretação é psicologista, porque mais difícil de comprovar que alguém está julgando pelas aparências é demonstrar as suas pretensões quando não há provas textuais. Com efeito, podemos subir numa canoa por vários motivos, até mesmo para simplesmente estar nela ou perambular sem traçar um rumo exato e ver onde vai aportar. Isto quer dizer que o texto de Cardoso faz sentido, mas seus enunciados extraídos da hermenêutica psicológica não podem ser demonstrados, pois as intenções e pretensões dos historiadores 'incautos' podem ser bem outras. Somente eles podem expressá-las, e tudo o mais que afirmarmos sobre os desejos e pretensões dos outros não passará de uma suspeita feliz. Não irá além de uma forma de conferir sentido às nossas interpretações.

Cardoso, no entanto, utiliza-se deste expediente outras vezes como, por exemplo ao indicar alguns pontos comuns entre os historiadores ligados aos Annales e os marxistas. ${ }^{14}$ Numa síntese de sua autoria, recorre às ambições, aos interesses e às preocupações dos historiadores vinculados à escola francesa. ${ }^{15}$ Ainda no mesmo texto, explica que o paradigma iluminista se deu conforme uma "perspectiva que pretendia estender aos estudos sociais o método científico", ${ }^{16}$ e que "... seus partidários escrevem uma história que pretendem científica e racional...” pois “... acreditava-se que fora de tal atitude básica o saber histórico não responderia às demandas surgidas". ${ }^{17}$ Ora, ambições, crenças, convicções, preocupações e interesses, quando não expressos claramente, são operações que supomos processadas no espírito das pessoas, e que Langlois e Seignobos aconselhavam recriar para o correto entendimento dos textos. Estaria Cardoso seguindo o manual de Langlois e Seignobos, recriando as operações que se processaram na cabeça dos historiadores incautos ligados à escola dos Annales? As coisas que passavam pela alma de Cardoso no momento em que escrevia o seu texto são impossíveis de precisar aqui, mas o autor recorreu aos interesses, às crenças, às convicções, às preocupações, às pretensões, aos fenômenos mentais, ou seja, psicológicos. As recorrências feitas pelo autor não são frutos de nossas suspeitas, e sim elementos textuais retirados de seu escrito.

É certo que Cardoso não desconhece a hermenêutica psicológica, uma vez que criticou alguns intérpretes do marxismo exatamente por recorrerem 
à psique de Marx e Engels, tratando “... Marxe Engels como se fossem perfeitos imbecis que teriam pretendido ver a base econômica, absurdamente, como uma espécie de glândula capaz de gerar idéias e instituições". ${ }^{18}$ Sua crítica é válida, porque ninguém pode comprovar cientificamente o que Marx e Engels pretendiam de fato, mesmo que possamos listar os enunciados em que as expressaram literalmente. Podemos argumentar que escreveram tais coisas com outros objetivos. Além disso, não há mérito algum em imbecilizar quem quer que seja. Todavia, Cardoso escreveu que esses intérpretes dos textos marxistas não leram as correções feitas por Engels e nem conhecem os aperfeiçoamentos que o marxismo sofreu. Pensamos que, igualmente, não seja uma boa atitude do pesquisador empenhar-se em idiotizar os intérpretes que recorrem ao psicologismo, ao contexto, ou à filologia, mesmo porque ele fatalmente se envolveria em um caso ou noutro. Como dissemos anteriormente, ninguém de nós nasce imune às tradições. Cardoso ridicularizou os intérpretes que achincalharam Marx e Engels. Se nos empenharmos em fazer chacotas do texto de Cardoso estaremos caindo naquilo que Gadamer chamou de armadilhas da linguagem.

É possível, pensamos, discutir idéias e apontar as falhas dos métodos sem o recurso à desmoralização das pessoas que pertencem e defendem outras perspectivas teóricas e se utilizam de outros métodos de interpretação. $\mathrm{O}$ ataque virulento ao oponente pode ser uma opção retórica amplificada com o recurso à hermenêutica psicológica. Tal ampliação emana do postulado de Schleiermacher de que o intérprete de textos deve empenhar-se em perceber coisas que "podem ter ficado inconscientes ao produtor original". A hermenêutica filosófica rechaça tal pressuposto. Vamos nos ater à demonstração do emprego dos métodos de interpretação feito em Cardoso e Vainfas e, ao mesmo tempo, tentando colocar-nos sem a pretensão da imunidade porque a função da hermenêutica filosófica é exatamente esta: fazer com que nos reconheçamos humildemente, movendo-nos dentro de tradições. Portanto, se devemos nos referir a alguma coisa que ficou inconsciente, é sobre a nossa psique que devemos nos voltar.

Quanto aos intérpretes de Marx e Engels, a hermenêutica filosófica, por ser uma perspectiva voltada à "reflexão de si", não é antipositivista nem contra o marxismo, e sim uma forma de fazer ciência considerando as determinações do momento compreensivo. Trata-se de uma atitude necessária a todo historiador que deseja evitar ou, ao menos, deixar evidentes as armadilhas da linguagem. Nessa perspectiva, nos deparamos com o dado de que a linguagem, pela força da tradição, nos conduz a dizer coisas que de outro modo não diríamos, e isto não acontece por falta de consciência ou de preparo intelec- 
tual, mas porque, de outro modo, ninguém compreenderia nossos textos. Assim, manifesta-se a força da linguagem no fazer compreensivo.

Para ilustrar, recorremos a estes enunciados de Cardoso. Ele escreveu que “...os pós-modernos costumam, com efeito, ser mais apodíticos e retóricos do que argumentativos: abundam em seus textos as afirmações apresentadas como se fossem axiomáticas e auto-evidentes, não sendo então demonstradas..." ${ }^{19}$ Sabemos perfeitamente que deste texto em que se apresenta uma possível característica dos pós-modernos, a de costumarem ser mais apodíticos e retóricos do que argumentativos, não podemos generalizá-la a todos os partidários do chamado pós-modernismo. Sabemos, igualmente, que esta não seria uma qualidade suficiente para caracterizar alguém como pós-moderno. Mas, pelo que foi demonstrado até aqui, a hermenêutica psicológica é um procedimento do qual resultam enunciados apodíticos e retóricos no sentido de que não podem ser demonstrados, podendo até ser classificados como axiomáticos e auto-evidentes, e isto é o resultado da aplicação do método.

A recorrência à psicologia dos sujeitos no fazer interpretativo nem por isso deixa de ser um procedimento funcional, pois nos permite compreender, de forma lógica, textos e situações. Apresenta, porém, o grande inconveniente de que jamais poderemos comprovar o que realmente passava pela mente de um autor no momento em que escrevia seu texto, ou o que pensava um sujeito quando praticava uma ação, a não ser que a coisa esteja expressa. Então, caracteriza-se o que Michel Foucault ${ }^{20}$ chamou de interpretação ou hermenêutica da suspeita.

Cardoso e Vainfas utilizam-se, pois, da hermenêutica psicológica, mas não os condenamos por isto. Ademais, se analisarmos detidamente nossos textos veremos que em algum momento seguimos o mesmo modelo interpretativo. Armadilhas da linguagem, força da tradição, dinâmica própria do fazer interpretativo, história residual, como diz Gadamer. Os organizadores de Domínios da história escreveram coisas que não poderiam demonstrar, mas não cremos que eles, Schleiermacher, Langlois e Seignobos, inclusive nós sejamos pós-modernos. Isto é uma evidência de que uma tradição pode ultrapassar as fronteiras dos contextos. Talvez uma das características dos pós-modernos seja a tentativa de evitar a interpretação psicológica e a hermenêutica contextual ou romântica, mas tal classificação se daria pela aplicação do método romântico.

O procedimento romântico, como já indicamos, consiste em compreender textos e acontecimentos colocando-os nos contextos em que ocorreram ou foram produzidos. Tais contextos podem ser recortados pelos vieses econômico, político, cultural, religioso, social, ou mesmo pela junção de todos estes aspectos, formando um quadro que oferece um sentido para o objeto 
que está sendo interpretado. A utilização do método contextual é igualmente verificável nos textos de Vainfas e Cardoso, e isto ocorre porque os modos de interpretação fazem parte do conjunto de coisas que executamos por força da tradição. Em outras palavras, os procedimentos hermenêuticos plasmam-se em nossos escritos pelo simples fato de que a escrita da história sempre implica alguma forma de compreensão. Esta somente se efetua quando o sentido se completa.

\section{O USO DO MÉTODO ROMÂNTICO}

O fazer hermenêutico nada mais é do que a operação compreensiva sem a qual existiriam somente textos incompreensíveis, mas isto não significa que a hermenêutica se esgota nos seus métodos. $\mathrm{O}$ uso dos procedimentos, no entanto, pode ser detectado nos textos porque um dos critérios básicos para que um método seja considerado científico é a sua reprodutibilidade. O caminho metodológico percorrido necessita oferecer a possibilidade de ser trilhado outras vezes e com o mesmo sucesso. Da aplicação deste resulta que podemos identificar os modelos de interpretação utilizados.

Examinemos, então, um texto de Vainfas. Num dos artigos de Domínios da história, intitulado História das mentalidade e história cultural, o autor faz uma "...contextualização da história das mentalidades no quadro maior da historiografia filiada ao movimento dos Annales". ${ }^{21}$ Segundo o texto, aquilo que é

(...) denominado por muitos como escola dos Annales, o grupo de historiadores liderados por Bloch e Febvre se constitui, antes de tudo como um movimento... uma sensibilidade, um conjunto de estratégias voltadas para combater um tipo de história que se fazia na França e que dominava a universidade no início do século atual. ${ }^{22}$

Ainda conforme o texto, a história dominante na universidade francesa era preocupada com fatos políticos, diplomáticos, militares, ciosa de documentos considerados autênticos, furtando-se ao diálogo com outras disciplinas.

O conjunto de estratégias desenvolvido para combater a história dominante, de acordo com o texto, surgia assim num contexto acadêmico, em meio a um combate entre intelectuais. Isto não quer dizer que, para Vainfas, o movimento intelectual em si é explicação suficiente para o surgimento da Nova História. O contexto, no entanto, oferece sentido ao objeto, já que, neste quadro, podemos saber o que é esta coisa chamada Nova História. Entre outros sentidos possíveis, trata-se de algo semelhante a um movimento intelectual 
surgido no meio acadêmico francês cujos partidários empenhavam-se no combate a um tipo de história que se escrevia no início do século atual. Recorrência ao contexto é prova do recurso à hermenêutica contextual.

O método aqui utilizado por Vainfas, no entanto, conduz a duas dificuldades insuperáveis. Em primeiro lugar, nenhum contextualista pode escapar à acusação de que os contextos foram inventados pelos intérpretes para conferir sentido aos textos e aos acontecimentos decifrados. Com efeito, os contextos não foram criados pelos deuses, pelos ventos ou pelas tempestades. São obras de narradores, explicadores e intérpretes. Além disso, consistem em uma construção seletiva porque o sujeito que trata de compreender utilizando-se deste método agrega aos contextos somente os aspectos que contribuem para a boa compreensão de um acontecimento ou de um texto. Desta forma, a compreensão contextual é sempre uma construção viciada, mas este não é o seu maior problema. O que torna reprovável o método contextual, ou seja, a hermenêutica romântica é o pressuposto da supremacia do presente sobre o passado e do intérprete sobre o interpretado.

Quando recorremos a um contexto do passado (e esta é a prática comum na escrita da história), em geral consideramos que hoje sabemos mais do que ontem, significando que conhecemos melhor as coisas que aconteceram ou os textos que foram escritos porque as pessoas envolvidas não possuíam o contexto. Se partimos do contexto do presente, consideramos que a nossa análise é melhor do que as feitas por pessoas que não recorrem ao quadro contextual. Se a nossa visão de história for decadentista, diremos que ontem sabíamos mais do que hoje, que as civilizações do passado foram superiores, e assim por diante.

A supremacia do passado conduz ao derrotismo. A perspectiva da superioridade do presente, em suas variedades, acarreta a ilusão da supremacia do intérprete. Não é por acaso que o texto de Vainfas se inicia com um manifesto apresentado por Geoffrey Lloyd para "...suprimir as mentalidades como objeto da história, sob a alegação de que elas exprimem um equívoco teórico". ${ }^{23}$ Vainfas comenta que a crítica não é nova e que a chamada Nova História abriu-se de tal modo a outros saberes e questionamentos estruturalistas, que pôs em risco a própria soberania e a legitimidade da disciplina, sobretudo em algumas versões ou "profissões de fé" da história das mentalidades. O resultado, como diz o texto, foi o declínio das mentalidades e a deserção dos historiadores a ela dedicados para outros campos ${ }^{24}$.

A interpretação feita por Vainfas é um exemplo da aplicação do método romântico, da tese de que hoje sabemos mais do que ontem porque, conforme o seu texto, os historiadores da Nova História aceitaram tantos questionamentos estruturalistas que o resultado foi a decadência das mentalidades e 
a debandada dos historiadores para outros campos do saber. Poderiam ter sido mais prudentes, aliás hoje enxergamos o contexto que os adeptos das mentalidades não vislumbravam; podemos ver seus erros e acertos, pois, como diz Vainfas, atualmente

(...) têm-se, de toda forma, com Ginzburg, Chartier e Thompson, três modelos possíveis de história da cultura os quais, embora de diferentes e até excludentes maneiras, reabilitam a importância dos contrastes e conflitos sociais no plano cultural, evitando, quando menos, as ambigüidades e concepções interclassistas e descritivas de algumas visões da história das mentalidades. ${ }^{25}$

"Sabemos mais que ontem" é o mote da hermenêutica romântica que, para além disso, não acoberta erros formais porque a aplicação do método garante que os sentidos se completem coerentemente. Por um lado, a coerência formal extraída dos objetos interpretados a partir da hermenêutica romântica não a isenta de seu parentesco com o discurso do progresso e não a impede de reproduzir as mazelas, as ingenuidades e os preconceitos do cientificismo racionalista e da fé na ciência; alimenta o preconceito contra outras formas de saber e outras culturas que narraram e interpretam os acontecimento passados e presentes sem recorrer aos contextos. Por outro lado, o que Vainfas escreveu pode ser verificável e bem pertinente, pois devemos identificar os erros do passado e aprender a evitá-los, mas a hermenêutica filosófica parte do princípio de que devemos primeiramente identificar e evidenciar nossas falhas no momento mesmo da interpretação.

Sabemos que todos esses percalços do método romântico podem ser minimizados e até evitados sem abandoná-lo, mas a falha principal do método está na perspectiva, uma vez que quem o utiliza identifica, demonstra e põe em evidência os erros e acertos dos outros sem que o produto de sua própria interpretação seja examinado; é como se o intérprete fosse um sujeito não afetado pela história. Aqui encontramos a fonte de muitas contradições que as reflexões da hermenêutica filosófica podem nos ajudar a reconhecer e a evitar, fazendo-nos voltar os olhos sobre nós mesmos na qualidade de intérpretes. Desta forma, devemos deixar claro, neste texto, que estamos nos movendo na tradição platônico-aristotélica porque compreendemos os escritos de Cardoso e Vainfas, mas descartamos o pressuposto de que a linguagem seja um instrumento ao nosso dispor. Tentamos evidenciar as tradições nas quais nos movemos sem pressupor que somos isentos à força das tradições e, por isto, evitando agir como se fôssemos superiores aos outros.

Nenhum intérprete é imune às armadilhas da linguagem, e não se conclua do que foi escrito até aqui que Vainfas se utiliza apenas do esquema in- 
terpretativo romântico, enquanto Cardoso se serve exclusivamente do método psicológico. Um olhar mais detido sobre os textos de Vainfas pode detectar o uso da metodologia proposta por Schleiermacher. Numa parte de seu texto, Vainfas escreveu que "animava os fundadores dos Annales a perspectiva de construir uma história interdisciplinar". ${ }^{26}$ Neste enunciado, a parte — trabalho dos historiadores vinculados aos Annales - adquire significado no todo - o estado de ânimo daquelas pessoas, as suas intenções, aquelas coisas que jamais poderão ser demonstradas.

Vainfas usou os dois métodos até aqui discutidos e Cardoso, igualmente. Num dos textos, escrito em cooperação, os dois autores fazem um comentário sobre os estudos de Lucien Febvre acerca da obra de Rabelais. Asseveram que,

(...) com efeito, foi com base numa exaustiva pesquisa do vocabulário presente naquela obra que Febvre, divergindo dos que afirmavam o ateísmo de Rabelais, demonstrou a "mentalidade pré-lógica" que caracterizava o homem europeu do século XVI, homem essencialmente religioso, e por isso mesmo, incapaz de descrer. ${ }^{27}$

Evidentemente, não se trata de contestar as teses de Febvre nos seus aspectos lógicos e de coerência interna. O sentido que podemos compreender é que, para Febvre, Rebelais não poderia não crer porque era um homem do século XVI, e homens daquela época ou que viveram naquele contexto eram incapazes de não crer.

Neste caso, os hermeneutas românticos recorreram a um contexto especialmente religioso ou cultural, a Europa do século XVI, e o enunciado adquiriu um sentido lógico. A compreensão efetuou-se porque a parte, a figura de Rabelais, encaixou-se no todo, o conjunto dos homens que viveram naquele contexto.

Se considerarmos que o ato de crer é radicalmente diferente da comprovação científica, os povos incapazes de descrer pertencem a uma mentalidade pré-lógica. Assim estabelecemos uma diferença nítida entre o contexto em que vivemos e aquele em que viveu Rabelais. Movemo-nos então em uma tradição bem próxima do positivismo comtiano, porque Comte dividia as etapas da história de forma bem semelhante: Idade Mítica, Metafísica e Científica. Isto evidencia que, nesta parte do texto, tanto Febvre quanto Cardoso e Vainfas moveram-se no interior da tradição positivista; mas confessamos que também nós, porque compreendemos os seus enunciados e não nos poríamos a defender que estejamos vivendo na mesma época que Rabelais. Pensamos que o trabalho do historiador não deve consistir em classificar épocas sempre demonstrando a superioridade da sua sobre as outras.

A tese de que os europeus do século XVI eram incapazes de descrer é ló- 
gica, coerente e faz sentido, mas comporta aquele grande inconveniente de fundamentar-se na supremacia do presente sobre o passado e do intérprete sobre o interpretado. A evidência disto é a expressão "mentalidade pré-lógica", cujo sentido, embora suspenso pelo uso das aspas, força a nossa adesão a certas tradições porque, como vimos, se considerarmos que Rabelais viveu em uma época anterior à nossa, em que a mentalidade era pré-lógica por força da linguagem, compreenderemos que seguiu-se à sua época o período da mentalidade lógica, uma vez que na tradição lingüística latina o prefixo "pré" indica aquilo que antecede alguma coisa. Se aceitarmos o pressuposto da tradição racionalista de que o pensamento lógico é superior a outras formas de conceber o mundo, a época em que viveu Rabelais será necessariamente inferior à seguinte. O texto de Cardoso e Vainfas não indica qual. Será esta em que vivemos? Pode ser... Neste caso, escreveríamos afirmando a superioridade do presente.

Não é evidente, contudo, que nossa época seja melhor do que as passadas ou futuras, nem é uma necessidade imperiosa afirmar a grandeza de nosso tempo. Importa considerar que fazemos isto por força de uma tradição, ou seja, devido ao uso do método hermenêutico contextual, procedimento fundamentado no pressuposto de que o intérprete pode executar sua leitura sem ser afetado pela linguagem. Tal incolumidade pode ser apontada como uma herança da estética de Aristóteles, para quem a bela linguagem era aquela em que o escritor ou falante se isentava, permitindo que a verdade e os fatos como que "falassem por si mesmos". Se, no entanto, admitirmos os efeitos da linguagem na produção de sentidos, perceberemos a importância do mundo pré-compreensivo e o valor da hermenêutica filosófica para a escrita da história.

Vainfas e Cardoso admitem a importância da hermenêutica, e para eles a arte de interpretar é “...definida em termos que hoje parecem ingênuos". ${ }^{28} \mathrm{No}$ vamente, o enunciado faz sentido, mas ali o esboço conceitual da hermenêutica está muito reduzido, posto que vinculado à proposta de Langlois e Seignobos. Estes historiadores incentivaram o uso do método interpretativo da hermenêutica psicológica para a escrita da história, e podemos dizer que alcançaram grande sucesso por meio desta sugestão, já que o procedimento é ainda utilizado em larga escala e até mesmo por seus mais severos críticos.

A hermenêutica, no entanto, não se reduz aos métodos psicológico e romântico. Segundo Gadamer, existe ainda o método filológico. Mais antigo e criticado, porém menos utilizado por historiadores de ofício, o procedimento filológico é igualmente um método de interpretação de textos. Consiste em descobrir o significado de uma parte do texto no seu todo. Assim, o sentido de uma frase, por exemplo, é dado pelo todo textual ao qual ela pertence.

Apontemos, sem mais delongas, que o método filológico é tão deficiente 
quanto o romântico e o psicológico, pois o filólogo, igualmente, não explicita na sua interpretação a sua pertença às tradições.

Concluímos, portanto, do que foi visto até aqui, que os três métodos hermenêuticos apresentam a mesma deficiência, isto é, não consideram a força da linguagem nas suas próprias interpretações e, neste sentido, podemos aproveitar a crítica tecida sobre a hermenêutica em Domínios da história, mas com a ressalva de que vale somente para os métodos, embora Cardoso e Vainfas tenham apenas se referido à proposta psicológica. O problema, então, localizase no espaço metodológico, pois quando utilizamos os procedimentos filológico, psicológico e romântico, reduzimos a arte de interpretar a simples métodos de compreensão. O fazer interpretativo não se reduz aos seus métodos ou a propostas metodológicas para a correta interpretação de textos e acontecimentos. A hermenêutica filosófica é uma proposta de inclusão da figura do intérprete no ato de interpretar. Renega a idéia de podermos analisar um texto fazendo-o expressar a sua muda verdade por meio de um método eficaz.

\section{HERMENÊUTICA FILOSÓFICA: INTERPRETAÇÃO INCLUSIVA}

As práticas interpretativas nas quais o texto é considerado como um objeto separado do intérprete sustentam-se na conjunção de duas antigas tradições: o racionalismo metódico e a estética de Aristóteles. A primeira é bastante evidente, conhecida e assumida. Trata-se do pressuposto de que os métodos nos auxiliam a evitar os erros, idéia brilhantemente defendida por Imanuel Kant. A teoria aristotélica da bela linguagem, como dissemos anteriormente, fundamenta-se na elisão do falante ou escritor.

Os procedimentos hermenêuticos que elidem a figura do intérprete fundamentam-se num dos pressupostos da teoria da linguagem instrumental, derivada do pensamento aristotélico. Tal pressuposição consiste em admitir que, na condição de intérpretes, não somos afetados pela linguagem no momento da compreensão, e disto resulta que sobrepujamos a antiga linguagem e criamos uma nova quando interpretarmos um acontecimento ou um texto. Segundo esta perspectiva, a linguagem é um instrumento por meio do qual nós, seres humanos, comunicamos nossos pensamentos uns aos outros, podendo utilizá-la conforme a nossa vontade.

A tradição grega equaciona pensamento e linguagem por meio da dialética, como se pudéssemos iniciar sempre uma linguagem nova sobre novos e antigos objetos, porquanto a condição básica é o fim das coisas antigas para que as novas adquiram existência. Esta concepção instrumental encontra-se na base dos métodos romântico e psicológico e representa a causa do empo- 
brecimento da interpretação porque exclui a autocrítica do intérprete no momento da compreensão. O intérprete não se ocupa em perceber o seu pertencimento às tradições, e por causa disto ocorre, às vezes, declarar-se contrário ao uso de teorias e métodos que ele mesmo utiliza. A concepção não-instrumental da linguagem vincula-se ao pensamento heideggeriano e apresenta-se como um modo de evitar tal embaraço.

Heidegger escreveu que a linguagem é a morada do ser, isto equivale a dizer que é o lugar onde os seres se dão à compreensão. Logo, nesta perspectiva, a linguagem não é instrumento porque não opera no modo dialético. Tese demonstrada por Gadamer e de onde se extrai o seguinte raciocínio: poderíamos começar agora a falar de um modo totalmente novo, ou seja, desconhecido para todas as pessoas, mas necessitaríamos traduzir o conteúdo de nossa comunicação, pois, do contrário, não seríamos compreendidos. Portanto, todas as coisas compreensíveis são enunciadas dentro de um "mundo dado," em que as palavras possuem sentidos que não podemos manipular ao nosso bel-prazer para que a comunicação se efetue. A impossibilidade da manipulação dos sentidos em vista de toda a compreensão é o fenômeno da pertença que afeta o intérprete e nos conduz às armadilhas da linguagem que a atitude hermenêutica pode ajudar a reconhecer, a evidenciar e a evitar.

Cardoso e Vainfas partem da concepção instrumental da linguagem e apresentam algumas sugestões metodológicas para os historiadores que se ocupam da interpretação de textos. Tal ponto de partida os conduz a sugerir que evitemos a hermenêutica em favor das técnicas da lingüística e da semiótica. Uma das propostas é a utilização do quadrado semiótico do qual os autores fazem uma demonstração, aplicando-o ao discurso de posse, na Presidência da República, do marechal Humberto de Alencar Castello Branco.

O trecho destacado para a interpretação deste discurso que se refere à compatibilidade entre desenvolvimento e democracia, se bem compreendemos, é o seguinte:

(...) portanto, que cada um faça a sua parte e carregue a sua pedra, nesta tarefa de soerguimento nacional. Cada operário e cada homem de empresa, este principalmente, pois a ele lembrarei esta sentença de Rui Barbosa: É nas classes mais cultas e abastadas que devem ter o seu ponto de partida as agitações regeneradoras. Demos ao povo o exemplo e ele nos seguirá. ${ }^{29}$

Segundo a interpretação feita pelos autores a partir do quadrado semiótico, o discurso de Castello Branco "revela um modo de raciocinar típico do pensamento conservador e antipopular. $\mathrm{O}$ fato de não estar investida a posi- 
ção $s_{2}$ que seria a liderança popular no desenvolvimento, mostra que tal coisa é considerada impossível ou impensável. ${ }^{30 "}$

O quadrado semiótico é bem útil e funcional para interpretarmos e classificarmos textos, identificando os modos pelos quais as outras pessoas raciocinam, no caso, o modo de pensar do marechal. Trata-se de um procedimento da hermenêutica filológica, uma vez que a compreensão efetua-se na base dos elementos textuais. A parte que é o dito sobre as classes mais cultas adquire sentido no todo que é o texto, a saber, o discurso sobre o desenvolvimento e a democracia. Mas, como se vê, os intérpretes analisam o texto como se a linguagem sobre a superioridade das elites fosse algo totalmente do outro, no caso, de uma das lideranças do regime militar.

A tradição da primazia das elites no desenvolvimento da história não é exclusividade do pensamento conservador e antipopular, pois sempre que compreendemos uma tradição estamos envolvidos, de alguma forma, por ela. Os próprios textos de Vainfas e Cardoso podem servir como evidência disto porque, na introdução aos Domínios da história, Cardoso acentuou que

(...) a inexistência, por enquanto, de teorias globais satisfatórias sem dúvida torna difícil a defesa de uma perspectiva holística, sem a qual não há como propor uma mudança do estado de coisas imperante em direção a um futuro distinto. ${ }^{31}$

A afinidade desta tese com o discurso de Castello Branco é evidente porque a construção de teorias globais tem sido historicamente uma tarefa dos intelectuais, digamos, de uma elite pensante. Evidentemente, trata-se de um enunciado articulado por um historiador, e outro, por um militar. Os objetivos e os contextos são diferentes e tudo o mais; porém, a tradição é a mesma porque confere a liderança a uma elite. Pode-se argumentar que se trata de discursos distintos, porque um é conservador e o outro revolucionário, mas os dois propõem mudanças no estado das coisas. O discurso do marechal e o do historiador articulam-se em um número maior de pontos do que gostaríamos que fosse: a língua é a mesma, e semelhantes a estrutura gramatical e o sentido das palavras. O quadrado semiótico, no entanto, foi aplicado exclusivamente sobre os enunciados do militar, por causa disto, os aspectos problemáticos da interpretação feita pelos historiadores não poderiam aparecer.

A falha do quadrado semiótico, da filologia, da hermenêutica romântica ou psicológica é sempre a mesma: o intérprete não volta o olhar sobre si mesmo. $\mathrm{O}$ uso destes métodos pode resultar em leituras coerentes e lógicas, mas não ajuda o intérprete a perceber-se e a explicitar-se como tal. A hermenêutica filosófica, desta forma, rompe com a doutrina iluminista pois o intelectual mudará, antes de tudo, o estado das coisas que imperam sobre si mesmo. 
As reflexões de Cardoso permitem que nos compreendamos como intérpretes românticos, psicologistas ou filólogos, visto que o autor fundamentouse nos escritos de Jean-Claude Gardin para definir os aspectos centrais do que chamou de tendência hermenêutica nas ciências sociais. Preferimos nos fundamentar nas ponderações de Gadamer e na sua proposta de uma hermenêutica filosófica. As razões desta escolha devem ficar claras nesta parte final.

O primeiro aspecto levantado por Cardoso, no enquadramento da tendência hermenêutica, é o princípio da dualidade natureza/cultura. Cardoso escreveu que os partidários desta tendência adotam o pressuposto de que "... o comportamento humano e seus resultados são essencialmente diferentes dos fenômenos estudados pelas ciências naturais, o que impede qualquer aproximação metodológica entre as duas". ${ }^{2}$

Ancorados na proposta gadameriana, defendemos que o reconhecimento da pertença do intérprete desloca o antigo dilema da duplicidade entre natureza e cultura, porque tanto uma quanto a outra são interpretadas. A hermenêutica filosófica não é um método para compreender ou explicar eficazmente a natureza ou a cultura. É a adoção de um posicionamento filosófico de auto-reflexão e autoconhecimento do intérprete que, enquanto realiza seu trabalho, torna explícita em seus textos a sua pertença, torna visíveis as armadilhas da linguagem, pondo a descoberto o mundo da pré-compreensão e evitando conduzir-se pela força dos sentidos preestabelecidos.

Tal mudança de perspectiva provoca naturalmente a reação contrária de qualquer pessoa acostumada ao objetivismo científico, e este é o segundo aspecto realçado por Cardoso. Consoante seu texto, a tendência hermenêutica nas ciências sociais nos conduz a

(...) afirmar ser desejável, no campo humano ou social, levar em conta o papel dos indivíduos e dos pequenos grupos, com seus respectivos planos, consciências, representações (imaginário), crenças, valores e desejos. Num outro nível, o do observador, seria preciso reconhecer que, com sua subjetividade, faz parte integrante daquilo que estuda - conduza isto ou não a recomendar alguma inefável 'empatia' com os indivíduos ou grupos tomados como objetos de estudo. ${ }^{33}$

Apesar da nossa inegável empatia com o texto de Cardoso, devemos considerar que a recomendação para estudar indivíduos e pequenos grupos, suas consciências, representações, crenças, valores e desejos não têm a ver, necessariamente, com a hermenêutica. Além disso, podemos fazê-lo utilizando-nos do método romântico, do psicológico, do filológico ou do analítico, uma vez que as consciências, as representações, os valores, as crenças e os desejos podem servir de contextos para a compreensão. Podem igualmente ser tomados 
como universo psicológico dos grupos e dos sujeitos, ou ainda podem ser simplesmente analisados como tais.

A tese de que o observador faz parte do objeto que estuda, própria da fenomenologia, não é relevante para a hermenêutica filosófica, porque não se trata de um estudo das subjetividades. O ponto fundamental em relação ao sujeito que interpreta é que este sujeito somos nós. Trata-se da inclusão do "eu intérprete" no fazer compreensivo, introduzindo a prática da autocrítica, que consiste em considerar que a linguagem usada por nós estava no mundo antes que aqui chegássemos, e não podemos inventar outra totalmente nova para expressar o que queremos, sob pena de cairmos no solipsismo. Não se trata, pois, de empatia ou indiferença, e sim de um questionamento constante sobre aquilo que dizemos e o modo pelo qual compreendemos as coisas.

Cardoso referiu-se a este constante questionar-se em que

(...) são postas em dúvida ou rechaçadas as formas usuais de validação do conhecimento. Neste ponto, as posições variam bastante, indo da subjetividade do autor individual ou do leitor implícito igualmente individual às posições de grupos de pessoas diversamente designados: "comunidade interpretativa", "comunidade textual", "sociedade discursiva”. Em qualquer hipótese, tratar-se-ia de um processo hermenêutico de interpretação, no caso da história tomado de empréstimo de preferência a uma certa antropologia, com maior freqüência a de Clliford Geertz ou alguma outra vertente do culturalismo relativista. ${ }^{34}$

O autor tem razão ao expressar que a hermenêutica filosófica nos leva a questionar as formas de validação do conhecimento consideradas como usuais, mas isto ocorre na medida em que a posição do intérprete no fazer compreensivo é sempre questionada. Este interrogar-se é o passo decisivo, o que não nos impede de analisar a forma como os outros interpretam seus textos e seus objetos, mas em nosso texto este olhar crítico deve estar voltado, antes de tudo, sobre nós que somos os intérpretes. Isto ocorre quando detemos nossa atenção no fazer interpretativo, na ação que une nosso trabalho e o daquele que escreveu o texto objeto de interpretação. Se compreendemos o que um autor diz é porque, de alguma forma, aprovando ou rechaçando partes do conteúdo que nos é transmitido, a tradição à qual pertence o texto que interpretamos chega até nós. Se assim não fosse, não poderíamos compreender nada do que foi escrito. Por isso, compreendemos sempre a partir de tradições, independentemente da existência de comunidades interpretativas, textuais e de sociedades discursivas. $\mathrm{O}$ costume de vincular a interpretação a um determinado grupo, elidindo a figura do intérprete, deriva do método român- 
tico de interpretação, procedimento que, como foi visto, difere em muito da hermenêutica filosófica.

Na perspectiva da hermenêutica gadameriana, o critério de validade do conhecimento está na própria dinâmica da interpretação: a compreensão se efetua quando o sentido se completa. Deste postulado Gadamer retirou que toda interpretação em que o sentido está completo é válida até que se apresentam as suas falhas. Podemos, no entanto, questionar a utilidade deste critério, pois se a hermenêutica filosófica fosse aplicada somente para compreender, criticar ou apoiar os textos alheios e os acontecimentos e fenômenos nos quais não estamos envolvidos, sua utilidade será mínima. Se, no entanto, conduzir-nos para a crítica do nosso fazer interpretativo, mais que útil, será indispensável para evitarmos as armadilhas da linguagem.

Não se trata, portanto, de um culturalismo relativista, e menos ainda de um intelectualismo absolutista, mas de uma resistência à força da linguagem, uma proposta de conhecimento e reconhecimento das coisas preconcebidas (a chamada estrutura da pré-compreensão), e de uma atitude crítica diante das tradições que nos envolvem para além do espaço delimitado das culturas, das classes sociais e do próprio discurso.

Cardoso ainda fez uma advertência em relação à “...inevitabilidade de uma multiplicidade de interpretações para cada objeto de estudo", mas consideramos que a multiplicidade de interpretações é um dado empírico e que "múltiplo" não é, a fortiori, sinônimo de incomensurável, irracional, subjetivo ou caótico. Concordamos com a tese de que o fazer interpretativo nos expõe ao perigo dos excessos. Voltamos, então, ao início deste texto: tanto é prejudicial ir longe demais quanto permanecer na imobilidade. Por isso, a atitude autocrítica da hermenêutica torna-se tão fundamental também para nós, que atuamos no campo do saber histórico, e nisto compartilhamos das palavras de Cardoso, uma vez que" particularmente influentes sobre os historiadores foram as reflexões relativas às formas da representação histórica, sendo esta última postulada como elemento constitutivo por excelência do pensamento histórico". ${ }^{35}$

Pensamos que o problema maior não é conceber o mundo como representação ou como processo, mas a forma pela qual nos percebemos dentro destas tradições.

\section{NOTAS}

'GADAMER, Hans-Georg. Verdade e método. 2ª ed.Petrópolis: Vozes,1997, p. 308.

${ }^{2}$ CARDOSO, Ciro Flamarion e VAINFAS, Ronaldo. Domínios da história: ensaios de teoria e metodologia. Rio de Janeiro: Campus, 1997, p. 375. 
José Adilçon Campigoto

${ }^{3}$ Idem.

${ }^{4}$ Idem.

${ }^{5}$ Em oposição ao sagrado.

${ }^{6}$ GADAMER, Hans-Georg. Op. cit., p. 299.

${ }^{7}$ Idem.

${ }^{8}$ CARDOSO \& VAINFAS. Op. cit., p. 11.

${ }^{9}$ GIUCCI, Guilhermo. Viajantes do maravilhoso: o novo mundo. São Paulo: Cia das Letras, 1992, p. 23.

${ }^{10}$ Idem, p. 24.

${ }^{11}$ Idem, p. 25.

${ }^{12}$ Idem, p. 33.

${ }^{13}$ NIETZSCHE, Friedrich W. Assim falou Zaratrustra. 4⿳亠丷a ed. Rio de Janeiro: Civilização Brasileira, 1987, pp. $212-213$.

${ }^{14}$ V. CARDOSO \& VAINFAS, 1997, p. 9.

${ }^{15}$ Idem, p. 8.

${ }^{16}$ Idem, p. 4.

${ }^{17}$ Idem.

${ }^{18}$ Idem, p. 12.

${ }^{19}$ Idem, p. 19.

$252{ }^{20}$ RABINOW, Paul; DREYFUS, Hubert. Michel Foucault: uma trajetória filosófica. Rio de Janeiro: Forense, 1995, pp. 118 - 120.

${ }^{21}$ CARDOSO \& VANIFAS. Op. cit., p. 128.

${ }^{22}$ Idem, p. 130.

${ }^{23}$ Idem, p. 127.

${ }^{24}$ Idem, p. 146.

${ }^{25}$ Idem, p. 158.

${ }^{26}$ Idem, p. 130.

${ }^{27}$ Idem, p. 377.

${ }^{28}$ Idem, p. 375.

${ }^{29}$ Idem, p. 388.

${ }^{30}$ Idem.

${ }^{31}$ Idem, p. 14.

${ }^{32}$ Idem, p. 16.

${ }^{33}$ Idem.

${ }^{34}$ Idem.

${ }^{35}$ Idem, p. 17.

Artigo recebido em 8/2003. Aprovado em 10/2003.

Revista Brasileira de História, vol. 23, nº 46 